\title{
Adequação das normas brasileiras de contabilidade à luz das normas internacionais: um estudo sobre o pronunciamento técnico CPC 04
}

A globalização, que levou à abertura de mercados de capitais e, consequentemente, a investimentos estrangeiros, implicou na necessidade das empresas adotarem uma Contabilidade com um padrão universal. No Brasil, um dos passos mais importantes para essa convergência foi a criação do Comitê de Pronunciamentos Contábeis (CPC), responsável pela adaptação dos padrões contábeis brasileiros às Normas Internacionais de Contabilidade ou IFRS (International Financial Reporting Standards). As IFRS propõem a padronização das demonstrações contábeis, tendo na contabilização dos Ativos Intangíveis, tratado no Pronunciamento Técnico CPC 04, que interpreta a IAS 38, um dos pontos polêmicos desta uniformização. A partir desses pressupostos, o presente artigo tem como objetivo, abordar os aspectos relevantes do Pronunciamento Técnico CPC 04. Para tanto, buscou verificar como se dá sua implementação com a finalidade de parametrizar o cumprimento das Normas Internacionais de Contabilidade. A metodologia aplicada é teórico-bibliográfica, extraindo-se as referências, que nortearam a pesquisa de dados primários contidos no Pronunciamento Técnico em análise, e de dados secundários, como livros, artigos, boletins informativos da área de Contabilidade assim como de publicações em sites relacionados ao assunto em questão. Os resultados apontaram que os principais pontos tratados, por ambas as normas, envolvem questões relacionadas à natureza e reconhecimento dos Ativos Intangíveis, à mensuração dos custos e à contabilização da amortização e das perdas por impairment destes ativos.

\section{Adequacy of Brazilian accounting standards in the light of international standards: a study on the technical pronouncement CPC 04}

\begin{abstract}
Globalization, which led to the opening of capital markets and, consequently, foreign investment, implied the need for companies to adopt Accounting with a universal standard. In Brazil, one of the most important steps for this convergence was the creation of the Accounting Pronouncements Committee (CPC), responsible for the adaptation of Brazilian accounting standards to International Financial Reporting Standards (IFRS). The IFRS propose the standardization of the financial statements, taking into account the Intangible Assets, treated in Technical Pronouncement CPC 04, which interprets IAS 38, one of the polemic points of this standardization. Based on these assumptions, this article aims to address the relevant aspects of Technical Pronouncement CPC 04. For this purpose, it sought to verify how its implementation is implemented in order to parameterize compliance with International Accounting Standards. The applied methodology is theoretical-bibliographical, extracting the references, which guided the research, of primary data contained in the Technical Pronouncement under analysis, and secondary data such as books, articles, newsletters from the Accounting area, as well as publications on sites related to the subject in question. The results indicated that the main points dealt with in both standards involve issues related to the nature and recognition of Intangible Assets, the measurement of costs and the accounting of amortization and impairment losses of these assets.
\end{abstract}

Keywords: Intangible Assets; Technical Pronouncements; International Accounting Standards.

Topic: Contabilidade Internacional

Reviewed anonymously in the process of blind peer
Received: $\mathbf{3 0 / 1 0 / 2 0 1 7}$

Approved: 30/12/2017

Alvani Bomfim de Sousa Júnior

Universidad Internacional Três Fronteiras, Brasil

http://lattes.cnpq.br/6358502728889050

http://orcid.org/0000-0002-8714-4175

alvanijunior@yahoo.com.br

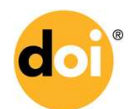

Referencing this:

SOUSA JÚNIOR, A. B.. Adequação das normas brasileiras de contabilidade à luz das normas internacionais: um estudo sobre o

DOI: 10.6008/SPC2179-684X.2017.003.0014 pronunciamento técnico CPC 04. Revista Brasileira de Administração Científica, v.8, n.3, p.171-182, 2017. DOI: 


\section{INTRODUÇÃO}

Ao longo dos anos, as constantes transformações do cenário econômico, principalmente no que diz respeito às empresas que operam em diversos países, as quais precisam apresentar informações sobre a situação patrimonial e financeira às suas controladoras, clientes, bancos ou fornecedores, dentre outros, sediados no exterior, passaram a exigir que tais informações tivessem o suporte de normas contábeis de qualidade. Desse modo, a padronização das normas e procedimentos contábeis alinhados com práticas internacionais, tornou-se um processo relevante para facilitar a análise das transações externas, proporcionando transparência e confiabilidade aos negócios das empresas em uma economia globalizada.

Em virtude dessa nova necessidade contábil, a partir da Lei 11.638 de 28 de dezembro de 2007, foram instituídas significativas modificações na Contabilidade brasileira, convergindo para padrões internacionais com vistas a facilitar o investimento estrangeiro no país. A normatização dos procedimentos, comtemplados com as mudanças estabelecidas por essa lei, ficou a cargo do Comitê de Pronunciamentos Contábeis (CPC), entidade autônoma criada pelo Conselho Federal de Contabilidade, através da CFC nำ1.055/05. O referido Comitê foi idealizado a partir dos esforços e comunhão de objetivos da Associação Brasileira das Companhias Abertas (ABRASCA), Associação dos Analistas e Profissionais de Investimento do Mercado de Capitais (APIMEC), Bolsa de Valores de São Paulo (BM\&FBOVESPA), Conselho Federal de Contabilidade (CFC), Fundação Instituto de Pesquisas Contábeis, Atuariais e Financeiras (FIPECAFI) e Instituto dos Auditores Independentes do Brasil (IBRACON).

Tendo como objetivo estudar, preparar e emitir Pronunciamentos Técnicos sobre procedimentos de contabilidade (LIMA et al., 2014), o CPC publicou, até o ano de 2013, além do Pronunciamento Conceitual Básico, quarenta e seis pronunciamentos que tratam de vários assuntos de natureza contábil e, em separado, o Pronunciamento Técnico para Pequenas e Médias Empresas (PME). Todos os pronunciamentos encontramse embasados, consistentemente, nas Normas Internacionais de Contabilidade (Internacional Accounting Standadrds- IAS), atualmente conhecidas como IFRS (International Financial Reporting Standards).

Nesse contexto, considerando-se que, neste milênio, os ativos mais importantes das companhias não são as fábricas ou máquinas (ativo imobilizado), declaradas como patrimônio no balanço, mas sim marcas, clientes ou as tecnologias que se desenvolvem, conhecidos como ativos intangíveis, o CPC publicou, diante da dificuldade de entendimento e compreensão deste tipo de ativo, o Pronunciamento Técnico 04, para facilitar sua avaliação nessa nova fase contábil.

Observado o disposto anteriormente, a pesquisa surge do seguinte questionamento: quais contribuições, pautadas nos princípios contábeis internacionais, se podem obter do estudo sobre o Pronunciamento Técnico CPC 04, como fonte de informação para as empresas brasileiras e profissionais da área? Diante dessa questão, a realização do presente estudo se justifica por ser fundamental o conhecimento sobre a correta mensuração e controle permanente dos ativos intangíveis, bem como a divulgação transparente de sua natureza, considerando-se, ainda, que a escolha da temática permite a abordagem de uma norma que deverá ser adotada em grande parte das instituições no país. 
O presente artigo tem, portanto, o objetivo de abordar os aspectos relevantes do Pronunciamento Técnico CPC 04, buscando-se, para tanto, verificar como se dá sua implementação a fim de parametrizar o cumprimento das Normas Internacionais de Contabilidade. Para organizar a discussão que envolve a temática, a metodologia aplicada é teórico-bibliográfica, extraindo-se as referências, que nortearam a pesquisa, de dados primários contidos no Pronunciamento Técnico em análise, e de dados secundários, como livros, artigos, boletins informativos da área de Contabilidade, assim como de publicações em sites relacionados ao assunto em questão.

\section{REVISÃO TEÓRICA}

\section{Contexto evolutivo da Contabilidade}

Afirmando ser o homem naturalmente ambicioso, ludícibus et al. (2000) cita que a necessidade do mesmo em contabilizar seus recursos advém desde o início da civilização. Alguns teóricos preferem dizer que a necessidade de contabilizar, ou seja, a Contabilidade existe, pelo menos, desde 4000 anos antes de Cristo, quando o homem, tendo ao seu lado um pequeno monte de pedras, separava uma para cada cabeça de ovelha, executando, assim, o que o contabilista chamaria, hoje, de inventário. Por outro lado, Sílvio Aparecido Crepaldi traz o entendimento de que a Contabilidade surgiu como uma parte do conhecimento humano, em função da necessidade básica do homem de contar seus rebanhos, produtos de sua pesca ou caça, objetivando garantir o resultado positivo da equação entre o imperativo de recursos e a disponibilidade para subsistência.

Pela análise de ludícibus et al. (2000) e de Sílvio Aparecido Crepaldi, torna-se possível verificar que a Contabilidade apareceu, ainda que de forma rudimentar, como um instrumento de medição e avaliação de bens, ligando as primeiras necessidades humanas de proteção à posse de suas riquezas individuais. Assim, desde o período primitivo, a Contabilidade se desenvolveu sempre em função das modificações das relações econômicas ocorridas no mundo, marcadas por períodos, definidos por Sá (1995, citado por ALBERTON, 2002) como:

Idade Antiga da Contabilidade; compreende a escrituração dos fatos patrimoniais pelos sumérios, babilônios, egípcios, assírios, cretenses, gregos, romanos e outras civilizações, no período de 6000 anos antes de Cristo a 1202 depois de Cristo;

Idade Média da Contabilidade: foi marcada pelo aparecimento do método do registro contábil pelas partidas dobradas, no período de 1202 a 1494;

Idade Moderna da Contabilidade: marcada pela divulgação das primeiras obras sobre a técnica dos registros patrimoniais, com destaque para a obra Tractatus, de Luca Pacioli, em 1494, e pelos estudos científicos de Francesco Villa, no ano de 1840;

Idade Científica ou Contemporânea da Contabilidade: marcada pela sistematização do conhecimento contábil, no período de 1840 até os dias atuais.

Em cada período, observa-se que a trajetória evolutiva da Contabilidade é dinâmica, caracterizada pela busca por formas mais eficientes de processar seus registros, procurando quebrar os paradigmas proporcionados nas diferentes idades de sua história. Nesse cenário, de acordo com Attie (1998, citado por ALBERTON, 2002), a Escola Italiana iniciou o processo de desenvolvimento da teoria da Contabilidade entre 1840 até 1920, quando, a partir deste período, passou a predominar a Escola Anglo-Americana de 
Contabilidade, desenvolvendo a Contabilidade de Custos, Gerencial, Análise de Balanços, Auditoria e outras ramificações técnicas.

Além dessas escolas, Schmidt (2000) menciona outras, como a Escola Alemã, no final do século XIX e início do século XX, que teve como principal contribuição o desenvolvimento doutrinário da Contabilidade, e a Escola Francesa ou Neocontista, também ao final do século XIX, que estabeleceu procedimentos para a elaboração dos balanços das empresas. 0 autor ressalta que, em 1880, foi realizado na França um congresso de contadores, no qual houve um consenso sobre a padronização dos balanços patrimoniais, sendo aprimorado o conceito de sociedade, tornando possível distinguir a entidade empresarial e os seus proprietários. A Contabilidade passando, então, a fazer parte dos princípios científicos, acompanha a evolução do sistema empresarial e das economias de mercado, podendo ser definida como:

A ciência - ou, segundo alguns, a técnica - destinada a estudar e controlar o patrimônio das entidades do ponto de vista econômico e financeiro, observando seus aspectos quantitativos e qualitativos e às variações por ele sofridas, com o objetivo de fornecer informações sobre o estado patrimonial e suas variações em determinado período. (FRANCO et al., 2001)

Reconhecida por uns como arte, para outros como técnica ou como ciência, a Contabilidade se caracteriza, sobretudo, por se constituir no conjunto ordenado de conhecimentos com objeto e finalidade definidos, o que permite enquadrá-la no elenco das espécies do saber humano. Na acepção ampla do conceito de ciência, enquadra-se como uma das ciências econômicas e sociais, cujo objeto de estudo é o patrimônio administrável à disposição das entidades econômico-administrativas, sobre o qual fornece as informações necessárias à avaliação da riqueza patrimonial e dos resultados produzidos por sua gestão (FRANCO et al., 2001).

Tais informações devem estar acessíveis e apresentar relativa facilidade de compreensão aos investidores, gestores e analistas financeiros de todo o mundo, o que exige mecanismos de evidenciação capazes de torná-las mais compreensíveis e, assim, facilitar a sua interpretação. No entanto, atualmente, evidencia-se que a situação econômica das organizações não tem sido homogênea no âmbito internacional, pois cada país tem suas próprias práticas contábeis, o que leva a diferentes resultados. Na prática, o que ocorre é que o lucro de uma empresa brasileira, por exemplo, não é o mesmo se adotadas as práticas contábeis de outros países, dificultando a compreensão dos usuários pela falta de uniformidade.

Para solucionar conflitos como esse, a comunidade internacional definiu que a forma mais adequada para atingir este objetivo, seria a uniformização dos padrões contábeis, possibilitando "o entendimento da viabilidade do negócio, a compreensão, a interpretação das demonstrações contábeis por acionistas estrangeiros e investidores e a comparação de informações entre companhias de um mesmo grupo ou de grupos distintos" (NAVAES, 2010). Sendo assim, as normas internacionais de Contabilidade uniformizam as ações a serem seguidas, viabilizando o entendimento das demonstrações contábeis e os resultados alcançados pelas companhias, independentemente de sua localidade. 


\section{Normas Internacionais de Contabilidade}

Partindo-se do pressuposto de que norma é a regulação de um determinado ponto específico, no campo contábil, esta regulação exerce significativa influência no reconhecimento, mensuração e divulgação das informações financeiras, pois representa o desenvolvimento de práticas que atendam aos anseios dos usuários no tocante à quantidade e qualidade das informações contábeis (CARDOSO et al., 2009 citado por NAVAES, 2010). Conforme esclarece a referida autora, as normas contábeis conformam as teorias e doutrinas relativas a essa ciência, norteando a atuação das organizações diante da realidade social, econômica e cultural, intervindo na sociedade por meio de órgãos regulamentadores, limitando o arbítrio das entidades pelas escolhas das práticas e normas utilizadas na elaboração dos relatórios financeiros.

As Normas Internacionais de Contabilidade (IAS), denominadas, a partir de 2003, como IFRS (International Financial Reporting Standard), representam, conforme Lima, Carmo e Martins (2014), um conjunto de pronunciamentos contábeis internacionais, publicados e revisados pelo IASB (International Accounting Standards Board), cujos membros são nomeados pela Fundação IASC (International Accounting Standards Committee).

Nesse ponto, cabe esclarecer que o IASC é o órgão superior que, resultante do consenso entre um grupo internacional de profissionais de Contabilidade, foi fundado em 1976, dotado de completa autonomia sobre a elaboração e publicação das normas internacionais de Contabilidade. Posteriormente, em 2001, constituiu-se o IASB, entidade independente do setor privado, sem fins lucrativos, que tem o intuito de proporcionar ajustes nas normas contábeis internacionais elaboradas pelo IASC, tornando-se, por conseguinte, responsável pela padronização de tais normas (NAVAES, 2010).

Ainda segundo Navaes (2010), o órgão de interpretação do IASB é o IFRIC (International Financial Reporting Interpretations Committee), projetado para ajudá-lo a melhorar os relatórios financeiros através da identificação, discussão e resolução de problemas de informação financeira no âmbito da IFRS. Sua principal atribuição é, pois, proporcionar uma orientação relevante sobre algumas questões contábeis, que possam receber tratamento contábil divergente ou inaceitável.

Desse modo, as IFRS foram criadas para harmonizar as normas contábeis e adequar os demonstrativos financeiros para apresentar, não só as informações quantitativas do patrimônio da companhia (lucros auferidos, dividendos a distribuir, posição financeira etc.), mas, também, as informações qualitativas, representadas pela melhor forma de evidenciação (disclosure ${ }^{1}$ ) possível.

Essas Normas internacionais de Contabilidade vêm sendo expandidas e aceitas por mais de 120 países, conforme dados da IASB, de 2012, atendendo ao objetivo de unificar a linguagem contábil nas demonstrações financeiras das empresas. A União Europeia as adotou, com maior abrangência, em 2005, passando a apresentar as demonstrações consolidadas de acordo com as IFRS. Um fator que favoreceu sua adoção, pelas empresas europeias, foi a exigência de instituições internacionais, como o Banco Mundial e a

\footnotetext{
${ }^{1}$ Em uma tradução livre, disclosure ou evidenciação significa revelação, divulgações de informações, podendo inclusive constituir uma quebra de confiabilidade (HENDRIKSEN et al., 1999, citado por NAVAES, 2010).
} 
Organização Mundial do Comércio, no que se refere ao emprego, por parte das empresas que pretendiam utilizar os serviços destas instituições como ajuda financeira, das Normas Internacionais de Contabilidade em suas demonstrações financeiras (ALMEIDA, 2012; PRADO, 2013).

Como principais benefícios na convergência contábil, percebem-se a redução da assimetria da informação, a maior eficiência do mercado, o aumento do grau de comparabilidade e a redução dos custos de capital para as empresas que adotam essa prática (FABIANO, 2012). Nessa perspectiva, a convergência para um padrão internacional de Contabilidade é motivada pelo movimento mundial de integração dos mercados de capitais, podendo decorrer por imposições legais das indicações institucionais das nações, dos incentivos concedidos para as empresas e das atitudes voluntárias de adoção das normas internacionais.

No caso do Brasil, a inserção no processo de convergência contábil internacional e aproximação de sua legislação aos países do mundo que já haviam adotado as normas IFRS, se concretizaram por meio da promulgação da lei 11.638, no final do ano de 2007, posteriormente modificada pela Medida Provisória n.o 449, de 3 de dezembro de 2008, que se transformou, posteriormente, na Lei 11.941/09.

\section{Convergência das Normas Contábeis Nacionais às Normas Internacionais}

No Brasil, até a década de 70, a Contabilidade foi marcada por forte influência fiscal, inclinada meramente à escrituração contábil para atender aos interesses do fisco, sendo o contador, muitas vezes, confundido com um funcionário do governo. Dessa forma, forneciam-se poucas informações sobre a situação econômica e financeira das entidades aos seus usuários, portanto, não voltadas à tomada de decisões (NIYANA, 2006). Com o passar do tempo e para atender aos interesses de novos usuários, como companhias abertas atuantes no mercado de capitais, instituições financeiras, seguradoras e governo, a Contabilidade foi, gradativamente, adaptada por instituições como a Comissão de Valores Mobiliários (CVM), Banco Central (BACEN), Secretaria da Receita Federal (SRF), Conselho Federal de Contabilidade (CFC), Instituto Brasileiro de Contadores (IBRACON), dentre outros.

Segundo Navaes (2010), o caminho para a integração do Brasil com as Normas Internacionais de Contabilidade (IFRS) foi iniciado com a Lei 11.638/07, denominada pelo mercado como a nova lei das S. A., que teve como objetivo principal atualizar a legislação societária brasileira para viabilizar este processo. Essa Lei trouxe importantes alterações nas normas contábeis, abrangendo modificações em determinados aspectos e essa transição teve a participação do Comitê de Pronunciamentos Contábeis (CPC), criado, em 2005, pela Resolução CFC no 1.055, cujos principais objetivos são:

Nas demonstrações financeiras obrigatórias; na escrituração do grupo de contas do balanço patrimonial e seus critérios de avaliação; na estrutura da Demonstração do Resultado do Exercício (DRE); na substituição da Demonstração das Origens e Aplicações de Recursos (DOAR) pela Demonstração dos Fluxos de Caixa (DFC); na inclusão da Demonstração do Valor Adicionado (DVA); na constituição e tratamento das reservas; nas transformações, incorporações, fusões e cisões e seus registros contábeis; e na avaliação dos investimentos em coligadas e controladas e seu tratamento contábil (SOTHE et al., citado por NAVAES, 2008).

[...] o estudo, o preparo e a emissão de Pronunciamentos Técnicos sobre procedimentos de Contabilidade e a divulgação de informações dessa natureza, para permitir a emissão de normas pela entidade reguladora brasileira, visando à centralização e uniformização do seu 
processo de produção, levando sempre em conta a convergência da Contabilidade Brasileira aos padrões internacionais. (LIMA et al., 2014)

Em suma, o trabalho do CPC consiste em estudar as normas internacionais de Contabilidade, traduzilas e, caso haja alguma divergência com as leis brasileiras, adequá-las. Após esse procedimento, o CPC coloca, via de regra, as normas em audiência pública para que o mercado (Ministérios do Governo Federal, Agências Reguladoras Federais, Conselhos Regionais de Contabilidade, Associações de Classe, Faculdades, Companhias Abertas, Empresas de Auditoria Independente, Professores, Contadores, Economistas, Alunos, entre outras pessoas interessadas) possa avaliá-las e sugerir melhorias. Logo, o CPC centraliza e uniformiza a produção de procedimentos contábeis em um único conjunto de normas, para aplicação no Brasil, adequado aos padrões internacionais.

Nessa condução, por exigência dos diversos órgãos reguladores contábeis brasileiros, a partir de dezembro de 2010, muitas empresas, no país, ficam obrigadas a adotar as Normas Internacionais de Contabilidade em suas demonstrações contábeis consolidadas. As empresas que, obrigatoriamente, devem aplicar as novas regras contábeis, são as seguintes: Companhias de Capital Aberto; Companhias de Capital Fechado; Sociedades de Economia Mista; Sociedade de Comandita por Ações; Sociedade de Grande Porte, tais como, Sociedade Limitada, Sociedade Simples, Sociedade Cooperativa, Sociedade em Nome Coletivo, Sociedade Comandita Simples (AZEVEDO, 2009, citado por NAVAES, 2010). Dentre as principais alterações produzidas pela Lei 11.638/07, encontra-se aquela relativa à criação de conta do Ativo Intangível, cujo tratamento contábil é abrangido no Pronunciamento Técnico CPC 04, foco do presente estudo.

\section{Ativos intangíveis conforme pronunciamento técnico - CPC 04}

Nas normas de contabilidade brasileira, os ativos intangíveis eram classificados dentro do ativo imobilizado, não sendo exigido que a sociedade divulgasse as mutações ocorridas, durante o exercício, numa conta específica de ativos intangíveis. Normalmente, eram divulgados somente os saldos, ao final do exercício, das principais classes desses ativos, com os demais bens do ativo imobilizado, junto com o custo e a amortização acumulada (ALMEIDA, 2006). No entanto, essa contabilização divergia das Normas Internacionais, segundo as quais se contabilizam os ativos intangíveis em conta específica, onde são lançados apenas os bens imateriais utilizados na manutenção da entidade.

$\mathrm{O}$ ativo intangível trata-se, portanto, de um desmembramento do ativo imobilizado que ganhou reconhecimento a partir das mudanças na elaboração e divulgação das Demonstrações Contábeis trazidas pela Lei no. 11.638. O tratamento desse tipo de ativo encontra-se no Pronunciamento Técnico CPC 04, que possui correlação com as Normas Internacionais de Contabilidade, especificamente com a International Accounting Standards 38 (IAS 38).

Esse pronunciamento apresenta três objetivos principais, que são: definir o tratamento contábil dos ativos intangíveis que não são abrangidos especificamente em outro Pronunciamento; estabelecer quando uma entidade deve reconhecer um ativo intangível; e, especificar como mensurar o valor contábil dos ativos intangíveis, exigindo divulgações específicas sobre esses ativos. Segundo definição do CPC 04, os ativos 
intangíveis são ativos não monetários, identificáveis, não possuem substância física, são controláveis e geradores de benefícios econômicos futuros.

No aspecto identificação, observa-se que um ativo intangível satisfaz este critério, quando for separável, isto é, pode ser separado ou dividido da entidade e vendido, transferido, licenciado, alugado ou trocado, seja individualmente ou em conjunto com um contrato, ativo ou passivo relacionado. Ainda, quando resultar de direitos contratuais ou de outros direitos legais, quer estes direitos sejam transferíveis, quer sejam separáveis da entidade ou de outros direitos e obrigações.

No que se refere ao controle, o CPC 04 menciona que 'a entidade controla um ativo quando detém o poder de obter benefícios econômicos futuros gerados pelo recurso subjacente e de restringir o acesso de terceiros a esses benefícios'. Muito embora a capacidade da entidade de controlar os benefícios econômicos futuros de ativo intangível advenha de direitos legais que possam ser exercidos num tribunal, a imposição legal de um direito não é uma condição imprescindível para o controle, visto que a entidade pode controlar benefícios econômicos futuros de outra forma. Quanto aos benefícios econômicos futuros, estes podem ocorrer através de uma receita de venda de produtos ou serviços, de uma redução nos custos ou de outros benefícios que sejam gerados em função desse ativo.

Nesses termos, no grupo do ativo intangível devem ser classificados ativos com a mesma natureza e utilização semelhante nas atividades da entidade. Segundo o mesmo Pronunciamento, existem classes distintas de ativos intangíveis como, por exemplo: marcas; títulos de periódicos; softwares; licenças e franquias; direitos autorais, patentes e outros direitos de propriedade industrial, de serviços e operacionais; receitas, fórmulas, modelos, projetos e protótipos; e ativos intangíveis em desenvolvimento.

No entanto, se o item for adquirido em uma combinação de negócios, passa a fazer parte do ágio derivado da expectativa de rentabilidade futura (goodwill), reconhecido na data da aquisição. Conforme os itens 62 e 63 do CPC 04, marcas, títulos de publicações, listas de clientes e outros itens similares, gerados internamente, não devem ser reconhecidos como ativos intangíveis, nem tampouco os gastos incorridos com marcas, títulos de publicações, listas de clientes e outros itens similares, que não podem ser separados dos custos relacionados ao desenvolvimento do negócio como um todo.

Os critérios de reconhecimento do ativo intangível, conforme CPC 04 e IAS 38, são os seguintes: quando for provável que os benefícios econômicos futuros esperados, atribuíveis ao ativo, serão gerados em favor da entidade; e quando o custo do ativo possa ser mensurado com segurança. O CPC 04 determina que todo ativo intangível seja mensurado, inicialmente, pelo seu custo, sendo este adquirido separadamente, incluindo seu preço de compra, acrescido de impostos de importação e impostos não recuperáveis sobre a compra, após a dedução dos descontos comerciais e abatimentos, e de qualquer custo diretamente atribuível à preparação do ativo para a finalidade proposta.

Os intangíveis devem ser amortizados já que representam benefícios vinculados a receitas geradas em períodos futuros, além disso, perdem seu valor ao longo do tempo, devendo ser amortizados durante o período estimado em que se espera ter o benefício (CAVALCANTE et al., 2002), entendendo-se como vida útil, o período de tempo em que se espera ter o benefício gerado pelo bem. Em termos de práticas 
internacionais, o IAS 38 deixa clara a postura a ser adotada: caso o intangível possua vida útil limitada, finita, deve ser amortizado, se por outro lado, possuir vida útil indefinida, deve ser objeto de testes de impairment periódicos.

De acordo com o CPC 04 (2008), a entidade deve avaliar se a vida útil do ativo intangível é definida ou indefinida e, se definida, a duração ou o volume de produção que constituem esta vida útil. $O$ ativo intangível com vida útil definida deve ser amortizado de forma sistemática, ao longo desse período estimado, com início a partir do momento em que o bem estiver disponível para uso, enquanto a de um intangível com vida útil indefinida, não deve mais ser amortizado, devendo ser submetido ao teste de impairment (perda de substância econômica).

Quanto à evidenciação, o item 118 do pronunciamento observa-se que a entidade, para cada ativo ou classes de ativos intangíveis (marcas, softwares, licenças e franquias etc.), deve divulgar, fazendo a distinção entre ativos intangíveis gerados internamente e outros ativos intangíveis, as seguintes informações: com vida útil indefinida ou definida e, se definida, os prazos de vida útil ou as taxas de amortização utilizadas; os métodos de amortização utilizados para ativos intangíveis com vida útil definida; o valor contábil bruto e eventual amortização acumulada (mais as perdas acumuladas no valor recuperável) no início e no final do período; a rubrica da demonstração do resultado em que qualquer amortização de ativo intangível for incluída; e a conciliação do valor contábil no início e no final do período.

Após isso, demonstra-se: adições, indicando separadamente as que foram geradas por desenvolvimento interno e as adquiridas, bem como as adquiridas por meio de uma combinação de negócios; ativos classificados como mantidos para venda ou incluídos em grupo de ativos classificados como mantidos para venda e outras baixas; aumentos ou reduções durante o período, decorrentes de reavaliações nos termos dos itens 75, 85 e 86 e perda por desvalorização de ativos reconhecidas ou revertidas diretamente no patrimônio líquido, de acordo com o Pronunciamento Técnico CPC 01 - Redução ao Valor Recuperável de Ativos; provisões para perdas de ativos, reconhecidas no resultado do período, de acordo com o Pronunciamento Técnico CPC 01 - Redução ao Valor Recuperável de Ativos (se houver).

Dando-se continuidade, tem-se: reversão de perda por desvalorização de ativos, apropriada ao resultado do período, de acordo com o Pronunciamento Técnico CPC 01 - Redução ao Valor Recuperável de Ativos (se houver); qualquer amortização reconhecida no período; variações cambiais líquidas geradas pela conversão das demonstrações contábeis para a moeda de apresentação e de operações no exterior para a moeda de apresentação da entidade; e outras alterações no valor contábil durante o período.

A divulgação dos ativos intangíveis é de grande importância para as entidades, razão pela qual quanto mais detalhada for a informação, mais ricas serão as demonstrações contábeis. O Pronunciamento Técnico CPC 04 recomenda a divulgação de todas as informações consideradas relevantes, mesmo não sendo obrigatórias, pois podem ser significativamente importantes para enriquecer as demonstrações contábeis da empresa. 


\section{METODOLOGIA}

O desenvolvimento da pesquisa deu-se por meio de pesquisa bibliográfica a partir de dados obtidos em livros, artigos científicos, revistas especializadas e Internet. Nos esclarecimentos de Gil (2010), a principal vantagem desse método é possibilitar ao investigador a cobertura de uma gama de acontecimentos com maior amplitude do que aquela que poderia pesquisar diretamente. Nesse sentido, implica em um trabalho de assimilação de conteúdos, de confecção de fichamentos e, sobretudo, de reflexão sobre a temática.

Diante da necessidade da compreensão do fenômeno estudado, de acordo com o objetivo proposto, a pesquisa ocorreu em dois momentos. No primeiro momento, a utilização de materiais bibliográficos, realizada por livros e artigos científicos, proporcionou sustentação teórica para a pesquisa. Na sequência, analisaram-se os estudos referentes às Normas Internacionais de Contabilidade que, neste caso, englobaram as teses, dissertações e artigos científicos, tanto os publicados em revistas como os apresentados em congressos brasileiros de Contabilidade, cruzando-os com as informações contidas no Pronunciamento Técnico CPC 04.

\section{RESULTADOS E DISCUSSÃO}

A partir da análise e sistematização das informações contidas nos diferentes estudos e documentos, particularmente no Pronunciamento Técnico CPC 04, verificou-se que a entrada em vigor da Lei 11.638/2007 causou mudanças nas normas contábeis brasileiras, harmonizando-as com as internacionais. 0 Pronunciamento, em questão, é meramente uma tradução da IAS 38, com pequenas adaptações à realidade brasileira, representando um avanço contábil, no país.

Para se aplicar corretamente a legislação brasileira, a IAS 38 e o Pronunciamento Técnico CPC 04 são convergentes na definição de ativo intangível, permitindo seu tratamento contábil tanto no objetivo quanto no alcance. Não obstante, observou-se uma diferença na orientação que trata da reavaliação de itens do ativo intangível, opção oferecida pelas Normas Internacionais de Contabilidade, prevista na IAS 38, pois o Pronunciamento Técnico CPC 04, apesar de manter o parágrafo relativo à reavaliação, cita expressamente 'se permitido legalmente'. Por conseguinte, em função da legislação brasileira, a reavaliação de ativos é proibida pela Lei 11.638/2007 e, portanto, não deve ser praticada nas demonstrações contábeis.

Há de se evidenciar outro distanciamento, relativamente ao que ocorre entre o que o mercado percebe como valor das empresas e o que registra a Contabilidade, mesmo de acordo com o padrão das normas internacionais. Segundo Martins (2002), "percebe-se o vulto que os ativos intangíveis estão tomando na economia atual. E a contabilidade ainda está aquém do desejado, no que tange a evidenciação desses ativos intangíveis". Isso porque, um dos principais valores não contabilizados por empresas no mundo e, também, no Brasil, é o valor atribuído a ativos intangíveis gerados internamente, os quais são fundamentais, porém complexos por sua subjetividade intrínseca, conforme esclarecem ludícibus et al. (2005).

Para ludícibus et al. (2005), tentar inserir, no ativo, o valor do Capital Intelectual ou do goodwill, por serem conceitos pouco suscetíveis de uma avaliação, talvez não seja totalmente responsável, mas nada 
impede de se fazer considerações de custo/benefício e de apresentar tais avaliações em quadros suplementares, indicando, com clareza, os critérios utilizados, por parte dos contadores.

Ressalta-se, igualmente, que a nova legislação contábil não se refere aos ativos do conhecimento, e sim aos ativos que são objetivamente e diretamente mensuráveis em termos de valor, demonstrando que o CPC 04, apesar de ser considerado um avanço em termos de contabilização, ainda não contempla a grande parte dos elementos dos ativos intangíveis do conhecimento. O capital intelectual e as marcas são exemplos significativos do que existe de mais complexo para reconhecimento e evidenciação. Sobre isso, Lev (2005, citado por GILLIO, 2011) explica que "a falta de mercado para a negociação, dificuldade para a negociação, a duração limitada (risco inerente) e a falta de controle completo são dificuldades para o reconhecimento contábil de ativos intangíveis".

Mas, de modo geral, pode-se analisar que a uniformização com a IAS 38, adotada no Brasil pelo pronunciamento Técnico CPC 04 - Ativos Intangíveis - permite um aumento da representatividade destes ativos das empresas, além de facilitar a interpretação e a validação das informações, diminuindo as dificuldades de entendimento dos múltiplos usuários.

\section{CONCLUSÕES}

Tomando-se como referência a concepção de ludícibus (2005, citado por GILLIO, 2011), segundo a qual a aplicação dos Pronunciamentos, Orientações e Interpretações do CPC garante às demonstrações contábeis a adequação necessária para que os relatórios sejam interpretados, comparados e analisados por usuários interessados, mesmo de outros países, apreende-se que a convergência para um único padrão contábil representa uma saída para tratar de itens globalizados e solucionar problemas de diferenças contábeis.

Alicerçando-se em tais considerações, esta pesquisa, que teve como principal objetivo abordar os aspectos relevantes do Pronunciamento Técnico CPC 04, distingue que este Pronunciamento está próximo aos entendimentos expressos pelas Normas Contábeis Internacionais, especificamente a IAS 38. Enfocando, particularmente, como se dá sua implementação a fim de parametrizar o cumprimento das Normas Internacionais de Contabilidade, observou-se que os principais pontos tratados, dentre outros, por ambas as normas, envolvem questões relacionadas, à natureza e reconhecimento dos ativos intangíveis, à mensuração dos custos e à contabilização da amortização e das perdas por impairment destes ativos.

Assim, as construções teóricas e documentais que balizaram a presente investigação, permitiram responder ao questionamento sobre quais contribuições, pautadas nos princípios contábeis internacionais, se podem obter do estudo sobre o Pronunciamento Técnico CPC 04, como fonte de informação para as empresas brasileiras e profissionais da área.

Com base nos dados coletados, identifica-se que a tendência mundial de adoção às normas internacionais, moldou a atual regulação existente no Brasil e afetou a estrutura da Contabilidade brasileira ao adotar novos paradigmas capazes de atender as demandas internas aos princípios validados internacionalmente. É indiscutível, portanto, que o profissional da área contábil tenha melhor compreensão 
dos pronunciamentos contábeis, tornando-se indispensável este conhecimento para atender, adequadamente, a forma de contabilização no âmbito internacional.

\section{REFERÊNCIAS}

ALBERTON, L.. Uma contribuição para a formação de auditores contábeis independentes na perspectiva comportamental. Tese (Doutorado em Engenharia de Produção) - Universidade Federal de Santa Catarina, Florianópolis, 2002.

ALMEIDA, M. C.. Normas internacionais de contabilidade. São Paulo: Atlas, 2006.

ALMEIDA, N. S.. Pronunciamentos contábeis brasileiros: evidências do entendimento dos auditores independentes do Brasil. Dissertação (Mestrado em Administração) Universidade Federal de Uberlândia, Uberlândia, 2012.

FABIANO, D.. O nível de comparabilidade contábil dos países do BRIC. Dissertação (Mestrado em Administração) Universidade Federal de Uberlândia, Uberlândia, 2012.

FRANCO, H.; MARRA, E.. Auditoria Contábil: normas de auditoria; procedimentos e papéis de trabalho; programas de auditoria; relatórios de auditoria. 4 ed. São Paulo: Atlas, 2001.

GIL, A. C.. Como elaborar projetos de pesquisa. 5 ed. São Paulo: Atlas, 2010.

GILLIO, L.. Aproximação entre contabilidade gerencial e contabilidade financeira com a convergência contábil brasileiro às normas IFRS. Dissertação (Mestrado) Universidade de São Paulo, São Paulo, 2011.
IUDÍCIBUS, S. A.; MARION, J. C.. Contabilidade Comercial. 4 ed. São Paulo: Atlas, 2000.

LIMA, I. G.; CARMO, C. R. S.; MARTINS, V. F.. Convergência das Normas Contábeis Brasileiras às Normas Internacionais de Contabilidade: um estudo sobre evidenciação adicional. Revista de Administração, v.12, n.21, p.37-54, 2014.

MARTINS, V.. Contribuição à avaliação do goodwill: depósitos estáveis, um ativo intangível. Dissertação (Mestrado) - Universidade de São Paulo, São Paulo, 2002.

NAVAES, B. M. P. L.. A harmonização das Normas Contábeis pela aderência à Lei 11.638/2007 e a MP 449/2008 em empresas multinacionais e do setor público: um estudo de múltiplos casos. Dissertação (Mestrado em Engenharia de Produção) - Universidade Federal do Rio de Janeiro, Rio de Janeiro, 2010.

NIYAMA, J. K.. Contabilidade Internacional. São Paulo: Atlas, 2005.

PRADO, Thiago Alberto dos Reis. Os impactos da primeira adoção das normas IFRS nas demonstrações contábeis das companhias abertas brasileiras. Dissertação (Mestrado em Administração) - Universidade Federal de Uberlândia, Uberlândia (MG), 2013.

SCHMIDT, P.. História do Pensamento Contábil. Porto Alegre: Bookman, 2000. 